Research Article

\title{
A study on prescribing pattern of antihypertensives in adult patients attending in a tertiary care hospital of Assam, India
}

\author{
Pavel Sikidar*, Pinaki Chakravarty, Ayan Purkayastha, Rohit Tigga
}

\begin{abstract}
Department of Pharmacology, Silchar Medical College and Hospital, Silchar, Assam, India
\end{abstract}

Received: 28 March 2016

Accepted: 27 April 2016

*Correspondence to:

Dr. Pavel Sikidar,

Email: pavelsikidar@gmail.com

Copyright: (C) the author(s), publisher and licensee Medip Academy. This is an openaccess article distributed under the terms of the Creative Commons Attribution NonCommercial License, which permits unrestricted noncommercial use, distribution, and reproduction in any medium, provided the original work is properly cited.

\begin{abstract}
Background: Hypertension is one of the most common chronic medical problems prompting visits to health care providers. It has been estimated that hypertension accounts for $13 \%$ of deaths worldwide. The main objective of the present study was to assess the pattern of drug utilisation and to evaluate whether the prescribing patterns for anti-hypertensive in our institution is in adherence with JNC 8 guidelines for treatment of hypertension.

Methods: A prospective, observational, non-interventional, hospital based study was carried out for the period of three months in an out-patient department. Adult patients of either sex who have been diagnosed with hypertension as per JNC-8 guidelines without co morbidities and patients receiving or prescribed with antihypertensive drugs were included. The analysis of the prescription frequency, proportion of the different antihypertensive classes of drugs as monotherapy as well as combination therapy was done.

Results: The most common drug classes involved in the study was angiotension II receptor antagonists followed by calcium channel blocker. The most common anti-hypertensive fixed dose combination therapy involved in the study was angiotensin II receptor antagonist+thiazide diuretic. $67 \%$ of the cases received monotherapy whereas remaining $33 \%$ received combination therapy.

Conclusions: Our study shows that the most commonly prescribed drug classes involved were angiotensin II receptor antagonists followed by calcium channel blocker and the anti-hypertensive drug combinations among hypertensive patients were considerable and this practice positively impacted on the overall blood pressure control.
\end{abstract}

Keywords: Drug utilisation, Prescription pattern, Antihypertensive drugs, JNC 8

\section{INTRODUCTION}

Hypertension is one of the most common chronic diseases leading to high mortality and morbidity. ${ }^{1,2}$ The report of World Health Organization 2002 states that hypertension is the primary or may be secondary cause in some cases for $50 \%$ of cardiovascular diseases and subsequent deaths worldwide. ${ }^{3}$ An extensive range of antihypertensive drugs are accessible for use in various combinations for efficient management. ${ }^{4-6}$ The choice of drug depends upon patient and other related factors. Recommendations of a variety of guidelines are available for treatment of hypertension, one such guideline is JNC 8 which suggests the rationale administration of drugs by providing algorithms for the treatment as per the stages of hypertension. JNC 8 suggests that for preliminary stage of hypertension thiazide group of drugs, alone or in combination are drug of choice.

For the second stage hypertension two drug regimens should be favoured, of which one should be thiazide diuretics. In view of the above factors, the following study was considered to analyse the prescribing patterns of antihypertensive drugs and to assess the adherence to JNC 8 guidelines in an out-patient department in a tertiary care hospital in southern Assam, India. Such drug utilisation studies help to assess and scrutinize the medical, social and economic outcomes of drug therapy. They are more significant and monitor the prescribing outlook of physicians with the endeavor to offer rationality. ${ }^{7,8}$ 


\section{METHODS}

A prospective, observational, non-interventional, hospital based study was carried out for the period of three months in medicine out-patient department (OPD) of Silchar medical college and hospital $(\mathrm{SMCH})$, a tertiary care institute located in the southern part of Assam, India. Adult patients of either sex who have been diagnosed with hypertension as per $\mathrm{JNC}-8$ guidelines and receiving antihypertensive drugs were included. The patients were categorised into two groups: age group $>60$ years and age group $<60$ years. Patients with any stage of hypertension only were included in the study. Those with comorbidities were excluded. The protocol was organized as per world health organisation (WHO) based guidelines (Appendix I) and the institutional ethical committee (IEC) of Silchar medical college and hospital duly accepted it. ${ }^{9}$ At the preliminary stage, with the exemption of the OPD in charge, other doctors were not knowledgeable about the study protocol in order to determine the current prescribing style and dispensing practice. The patients who co-operated were interviewed and data gathered through patient counselling and selfobservation in a semi-structured coded proforma. Information was collected from chronically-ill patients who visited SMCH OPD, such as those afflicted with hypertension, only by using their individual health cards. The JNC 8 guidelines were considered as standard for assessment of adherence and drug utilisation.

\section{RESULTS}

During our study we gathered a total of 300 prescriptions as per inclusion criteria. Out of 300 prescriptions 174 were of male patients and 126 were of female patients (Figure 1).The patients were categorised into two groups, those above 60 years of age and those below 60 years of age (Figure 2).Out of 300 patients, 201 patients (67\%) received monotherapy, 90 patients $(30 \%)$ received two drug therapy and 9 patients $(3 \%)$ received three drug therapy (Figure 3).

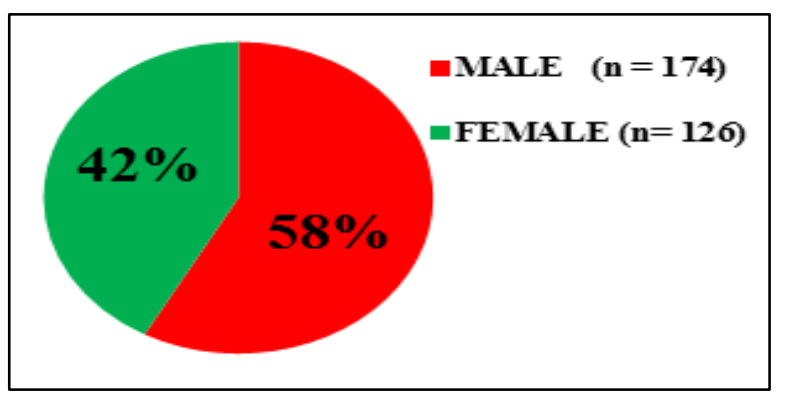

Figure 1: A pie-diagram showing percentage sex distribution of the patients.

Now among the patients receiving drug monotherapy, 87 patients (29\% of total 300 patients) received angiotensin receptor blockers (ARBs), 72 patients $(24 \%)$ received calcium channel blockers (CCBs), 18 patients $(6 \%)$ received angiotensin converting enzyme inhibitors (ACE) and 24 patients (8\%) received diuretics (Figure 4).

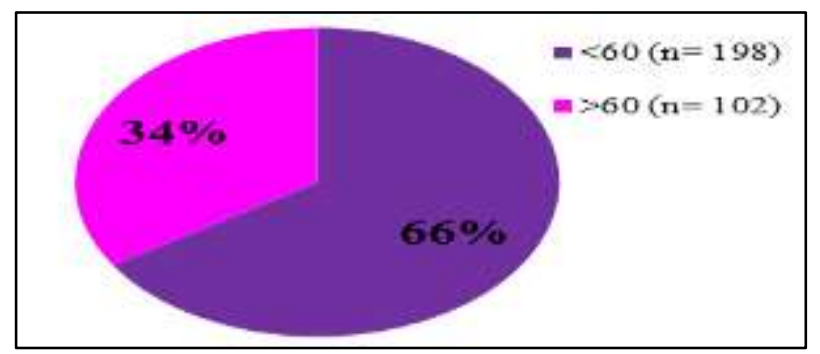

Figure 2: A pie diagram showing percentage age-distribution of the patients.

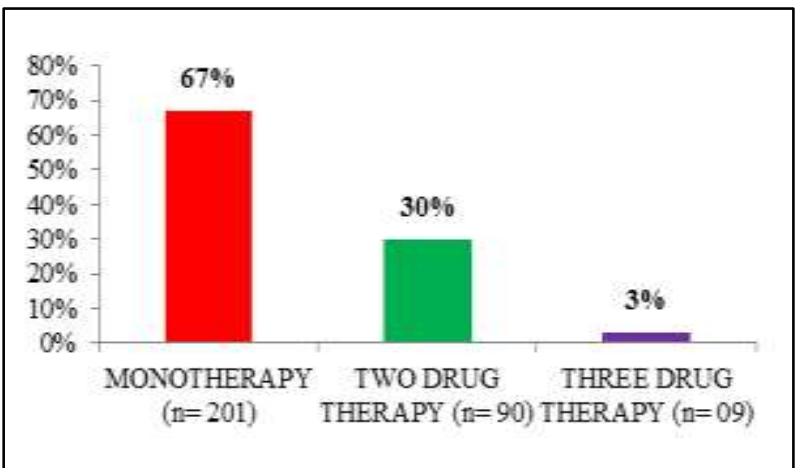

Figure 3: A bar diagram showing the percentage of patients receiving different drug combinations.

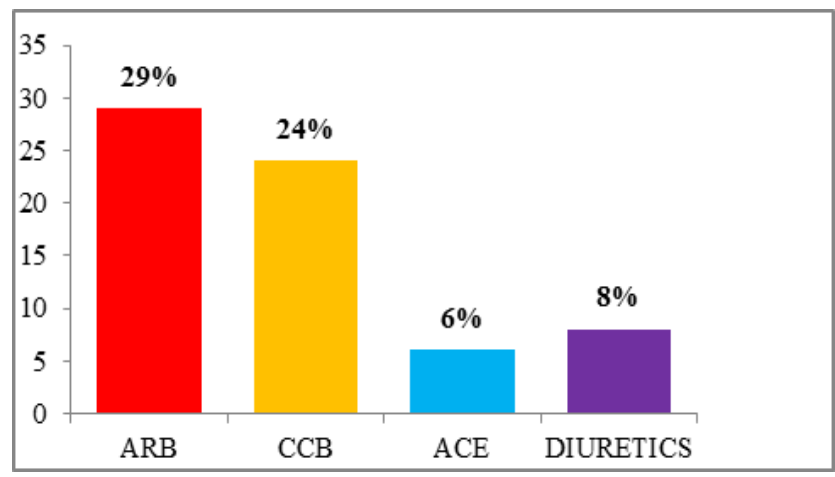

Figure 4: A bar diagram showing percentage distribution of patients receiving various groups of drugs.

Among the individual drugs, 72 patients in total (24\%) received amlodipine, 69 patients $(23 \%)$ received telmisartan, 18 patients $(6 \%)$ received olmesartan, 12 patients $(4 \%)$ received enalapril, 12 patients (4\%) received furosemide, 9 patients $(3 \%)$ received hydrochlorthiazide, and 3 patients $(1 \%)$ each received ramipril, lisinopril and torsemide respectively (Figure 5).

Among two drug combinations, 42 patients in total (14\%) received a combination of $\mathrm{ARB}$ and diuretics, 30 patients $(10 \%)$ received a combination of $\mathrm{ARB}$ and $\mathrm{CCB}, 12$ patients (4\%) received $\mathrm{CCB}$ and Diuretics and 6 patients 
(2\%) received a combination of $\mathrm{CCB}$ and beta-blocker (BB) (Figure 6).

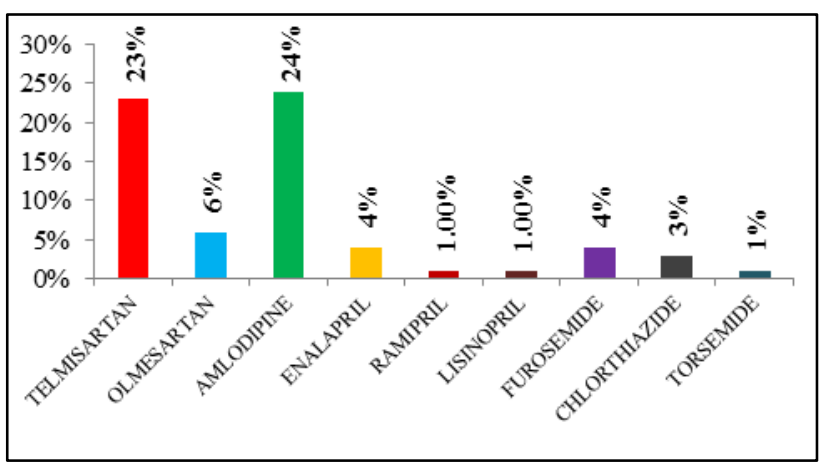

Figure 5: A bar diagram showing percentage distribution of patients receiving individual drugs.

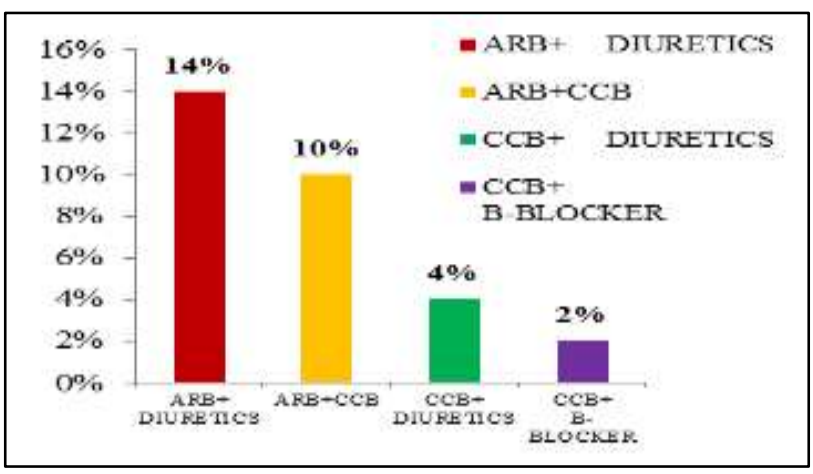

Figure 6: A bar diagram showing percentage distribution of patients receiving two drug combinations.

Among those receiving three drug combinations, 2 patients $(0.67 \%)$ were prescribed a combination of $\mathrm{ACE}+\mathrm{BB}+\mathrm{CCB}, 4$ patients $(1.33 \%)$ were prescribed $\mathrm{ARB}+\mathrm{CCB}+$ Diuretics and 3 patients $(1 \%)$ received $\mathrm{ARB}+\mathrm{BB}+$ Diuretics (Figure 7).

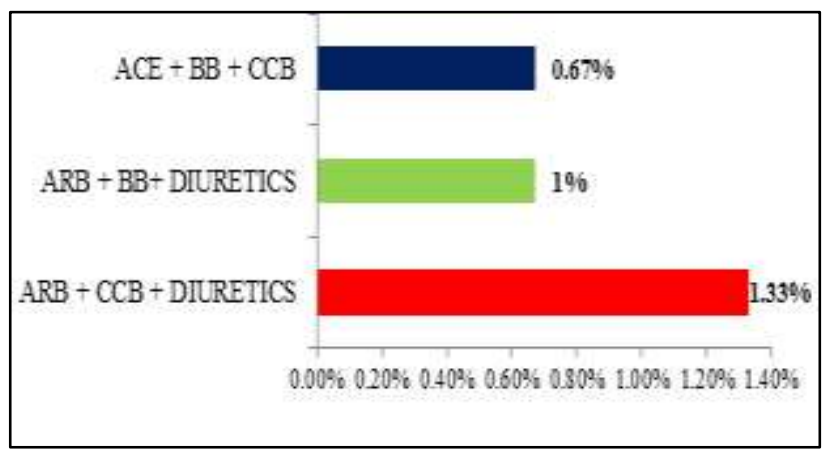

Figure 7: A bar diagram showing the percentage distribution of patients receiving three drug combinations.
A prescription based survey is one of the most efficient methods to measure and estimate the prescribing mind-set of physicians and dispensing tradition of pharmacists. ${ }^{10} \mathrm{It}$ is also important to take into consideration the guidelines of international regulatory bodies in order to improve the standard of prescribing behaviours and promote rational use of drugs. Our study is an effort in this regard to obtain feedback from practitioners and hence assess the rationality of drug use in our institution. Our study revealed that hypertension is more prevalent amidst males $(58 \%)$ than females $(42 \%)$. These observations are similar with those of Jhaj et al in their study prescribing patterns and cost of antihypertensive drugs in an internal medicine clinic. ${ }^{11}$ Monotherapy was given in $67 \%$ cases and $33 \%$ cases received combination therapy. Combination therapy seems to be a rational approach to reduce the cardiovascular mortality. ${ }^{12}$ Our study shows that most frequently prescribed classes of drugs are ARBs alone or in combination. Since the eighth report of Joint National Committee (JNC 8) on detection, evaluation prevention and treatment recommends the use of angiotensin receptor blocker for the management of early stage hypertension alone or in combination with other classes, thus suggesting that the above trend is in conformity to the recommendations of JNC 8 guidelines. In our study we observed that the utilization rate of diuretics as monotherapy was low (8\%) as compared to ARBs (29\%) and CCBs (24\%).Although diuretics are recommended as initial first line therapy for hypertension by JNC 8 guidelines, the reason behind their lower use could be due to adverse effect of diuretics on glucose homeostasis and lipid profile. ${ }^{13}$ In the present study we observed that $30 \%$ patients received combination therapy. The most frequent combination being ARB and Diuretics (14\%) followed by $\mathrm{ARB}$ and $\mathrm{CCB}(10 \%)$. It was observed that $3 \%$ cases received three drug combinations of which the most preferred combination was that of ARB, CCB and diuretics $(1.33 \%)$

\section{CONCLUSION}

At the end of our study we conclude that hypertension is more common in males than in females, and its prevalence seems to follow an increasing trend with increasing age. Angiotensin receptor blockers are the most frequently prescribed classes of drugs alone or in combination. This fact supports prescription adherence to JNC 8 guidelines. The incidence of hypertension is dependent upon several factors like ethnicity, genetic, environmental and physiological factors, hence further studies are necessary to set up a rationale or pattern for the choice of medication; taking into consideration the demographic factors involved in the prevalence of hypertension. 
The authors would like to thank to their colleagues from the departments of Medicine, Silchar Medical College and Hospital, India for cooperating with them and helping them to achieve what they desired to.

Funding: No funding sources Conflict of interest: None declared

Ethical approval: The study was approved by the Institutional Ethics Committee

\section{REFERENCES}

1. Collins R, Peto R, Mac MS, Hebert P, Fiebach NH, Eberlein KA, et al. Blood pressure, stroke and coronary heart disease. Part 2.Short-term reductions in blood pressure: overview of randomised drug trial in their epidemiological context.Lancet. 1990;335:827-38.

2. Hansson L. The benefits of lowering elevated blood pressure: a critical review of studies of cardiovascular morbidity and mortality in hypertension. J Hypertens. 1996;14:537-44.

3. Guilbert, JJ. The world health report 2002: Reducing risks, promoting healthy life. Educ Health. 2003; 16:230.

4. Hansson L, Dahlof B, Gudbrandsson T, Hellsing T, Kullman S, Kuylenstierna J, et al. Antihypertensive effect of felodipine or hydralazine when added to beta-blocker therapy. J Cardiovasc Pharmacol. 1988;12:94-101.

5. Kjeldsen SE, Farsang C, Sleigh P, Mancia G, World Health Organization; International society of hypertension. 1999 WHO/ISH hypertension guidelines-highlights and esh update. J Hypertens. 2001;19:2285-8.

6. Ramsay LE. British hypertension society guideline for hypertension management: summary. Br Med J. 1999;319:630-5.

7. Kapoor B, Raina RK, Kapoor S. Drug prescribing pattern in a teaching hospital. Ind $\mathrm{J}$ Pharmacol. 1985;17(1):168.

8. Pradhan SC, Shewade DG, Shashindran CH, Bapna JS. Drug utilization studies. National Med J India. 1988;1:185.

9. Bimo, Chowdhary A, Das A, Diwan V, Kafle KK, Mabadeje B, et al. In: how to investigate drug use in health facilities (selected drug use indicator) action programme on essential drugs. WHO official publication. 1995:68.

10. Yuen YH, Chang S, Chong CK, Lee SC, Critchlev JA, Chan JC. Drug utilization in a hospital general medical outpatient clinic with particular reference to antihypertensive and antidiabetic drugs. J Clin Pharm Ther. 1998;23:287-94.

11. Jhaj R, Goel NK, Gautam CS, Hota D, Sangeeta B. Prescribing patterns and cost of antihypertensive drugs in an internal medicine clinic. Ind Heart $\mathrm{J}$. 2001;53:323-27.

12. Mancia G, Grassi G. Antihypertensive treatment: past, present and future. J Hypertens. 1998;16:1-7.

13. Prisant LM, Beall SP, Nicholads GE, Feldman EB, Carr AA, Feldman DS, et al. Biochemical, endocrine, and mineral effects of indapamide in black women. $\mathrm{J}$ Clin Pharmacol. 1990;30:121-6.

Cite this article as: Sikidar $\mathrm{P}$, Chakravarty $\mathrm{P}$, Purkayastha A, Tigga R. A study on prescribing pattern of antihypertensives in adult patients attending in a tertiary care hospital of Assam, India. Int J Basic Clin Pharmacol 2016;5:975-8. 